\title{
Intertrochanteric Femoral Neck Fractures Treated by External Fixation
}

\author{
Professor Mahmood A Aljumaily*, yakdhan al saleem*, Saher H Albanna* \\ *Department of Surgery, Collage of Medicine , University of Mosul , Mosul , Iraq \\ Correspondence: yakdzuhdaw@uomosul.edu.iq
}

(Ann Coll Med Mosul 2021; 43 (1):16-20).

Received: $8^{\text {th }}$ Febr. 2021; Accepted: $25^{\text {th }}$ April 2021.

\section{ABSTRACT}

Background: Intertrochanteric femoral fracture (ITFF) is common injury in old age group, there are many options of treatment. External fixation used in the high risk patients.

Objective: To present a case series of ITFFs treated by external fixators.

Patients and method: Twenty six patients with ITFF were treated by external fixation in Alzahrawy private hospital in Mosul, during the period from July 2017 through October 2019.

Results: The mean time of follow-up was 11 months. Twenty two patients showed full union of the fracture by the end of the $4^{\text {th }}$ month and the external fixators were removed. Two patients died due to unrelated medical diseases, and one patient developed pathological fracture in the shaft of femur. The patients had good range of motion in both hip and knee joints. Pin tract infection was the commonest complication.

Conclusion: External fixation is simple, mini-invasive, cost-effective alternative method in the treatment of intertrochanteric femoral fractures.

Keywords: Intertrochanteric, Femoral Neck, Fracture, External, Fixation.

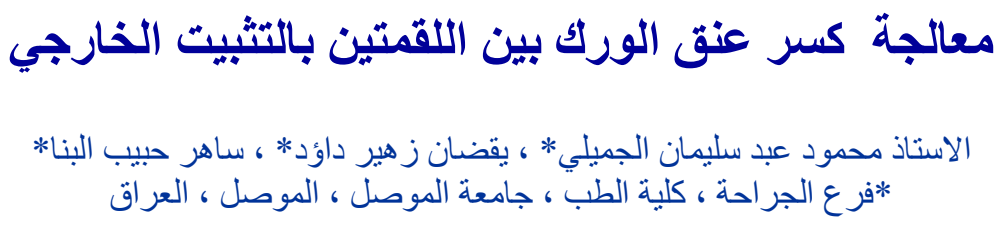

الخلفية: كسر عنق الورك بين اللقمنين من الاصدابات الثنائعة في كبار السن وهنالك خبار ات متعددة في العلاج. يستخدم التثبيت

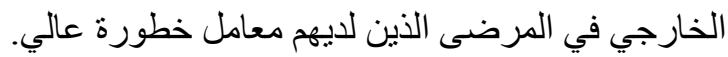

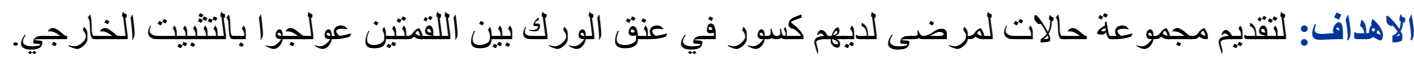

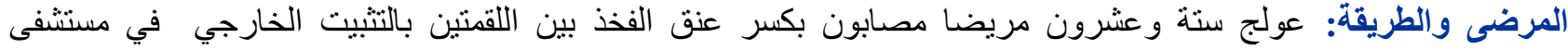

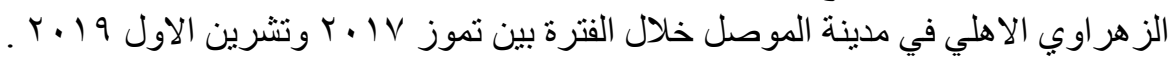

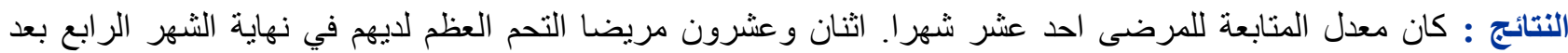

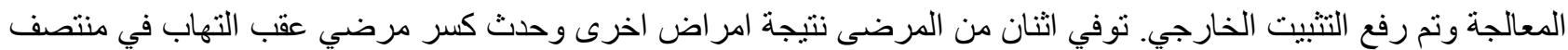

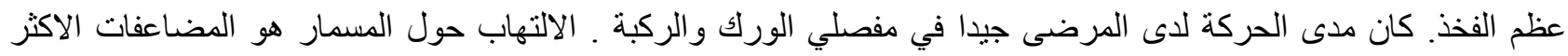
الاستنتاج: التثبيت الخارجي طريقة بسيطة محدودة التداخل وقليلة التكلفة وفعالة كبديل لعلاج كسر عنق الفخذ بين اللقمنين. 


\section{INTRODUCTION}

ntertrochanteric fracture of femoral neck is common disabling injury in old age group and usually associated with medical comorbidities ${ }^{1,2}$. Surgical treatment by internal fixation is the gold standard way of treatment to achieve early pain relief, prevent malunion, and allow early mobilization and effective nursing care ${ }^{1}$. The preferable surgical treatment is by locked intramedullary nail or sliding screw with plate ${ }^{1}$. Conservative treatment is limited to those who are not fit for surgical intervention and it carries high risk of compliations ${ }^{1}$.

The first external fixation in intertrochanteric fractures was reported by Scott at 1957. The high rate of complications especially pin tract infections, mechanical failure, and loosening limit its use ${ }^{3}$. In the last two decades, with development in external fixation, it started to be used again widely in intertrochanteric fractures as a good alternative in high risk patients ${ }^{4-6}$. A specially designed external fixation device had been used in these cases ${ }^{4,5,7}$.

During this study, Mosul was just liberated from ISIS occupation, which continued for three years following many years of destructive war and damage to most of hospitals and health facilities with a huge loss in most of the civil infrastructures with migration and poverty. The aim of this study was to present the results of external fixation in intertrochanteric fracture as a minimally invasive, simple surgical treatment when there is shortage of surgical facilities at time of crises.

\section{PATIENTS AND METHODS}

This work was approved by the scientific research ethical committee at the college of medicine in university of Mosul, ref. no.: UOM/ COM/ MREC/2020 (7) at 11/2/2020. During the period from July 2017 to October 2019, twenty six ambulatory patients with intertrochanteric fracture treated by external fixation were included in this study. The mean age of the patients was 68 years (range 55- 86 years), there were 11 males and 15 females. The average time from fracture to operation was 3 days ranged between 1 to 9 days. The right side was affected in 12 patients, while the left side was affected in 14 patients. Twelve of the fractures were type I according to classification by Kyle ${ }^{1}$, while 8 type I I, 5 type I I I, and one fracture was type IV (Figure $1 \mathrm{a}, \mathrm{b}$ ). All patients gave history of fall on the ground. Patients with multiple fractures, pathological fractures, previous hip fractures, dementia, or patients with the fracture history longer than 10 days were excluded from this study.

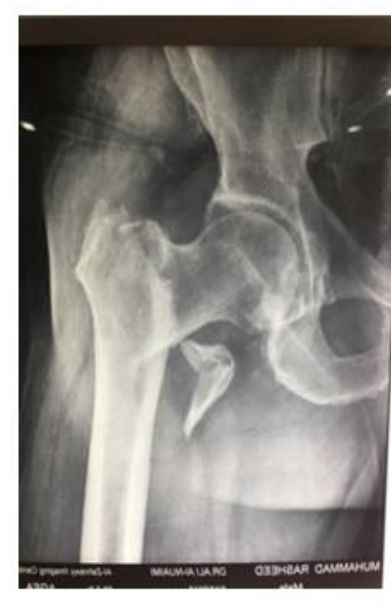

A

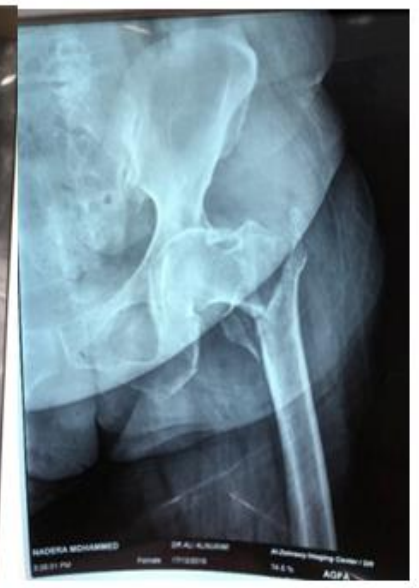

B figure 1: A - Displaced grade I I intertrochanteric fracture, B - Displaced grade I I I intertrochanteric fracture.

All patients were treated at Alzahrawy private hospital with closed reduction on orthopaedic table under spinal anesthesia in 15 patients, or general anesthesia in 11 patients. Under control of image intensifier, the fracture was reduced by traction, internal rotation and abduction. When satisfactory reduction was achieved and checked by image intensifier, percutaneous introduction of two or three $4.5 \mathrm{~mm}$ cortical Schanz pins in femoral neck and head performed by low speed drill under control of image intensifier. Other three $4.5 \mathrm{~mm}$ cortical Schanz pins were introduced in femoral shaft and all the pins were connected by $\mathrm{AO}$ external fixator and the position was checked by $x-$ ray. Sterile dressing was applied around the pins. the patients were discharged from hospital in the first or the second day. Early active mobilization of knee and quadriceps exercises were encouraged without weight bearing. One gram of intravenous ceftriaxone as prophylactic antibiotics was administered immediately before surgery and repeated every 12 hours for two days postoperatively together with analgesia. The patient's family was instructed to apply povidone iodine around pin entry daily with local dressing. The patients were encouraged to sit and to do active exercises in the affected lower limb with repeated changing of position. In the $2^{\text {nd }}$ postoperative month patients started with stand walker with non-weight bearing. In the third postoperative month gradual walking was started on walker. Full weight bearing was delayed at least 4 weeks after removal of pins when full clinical and $X$-ray evidence of fracture union was achieved. 
Postoperative checkup was done after two weeks in first month, and then monthly or as needed while patients were mobilized gradually on light walker. Radiographs were taken monthly. All fractures were united by the end of the $4^{\text {th }}$ postoperative month (Figure $2 \mathrm{a}, \mathrm{b}$ ).

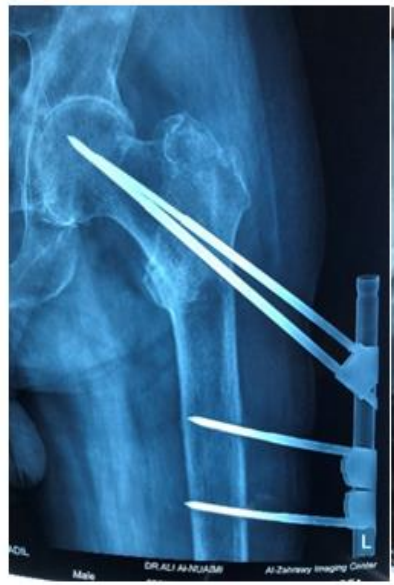

A

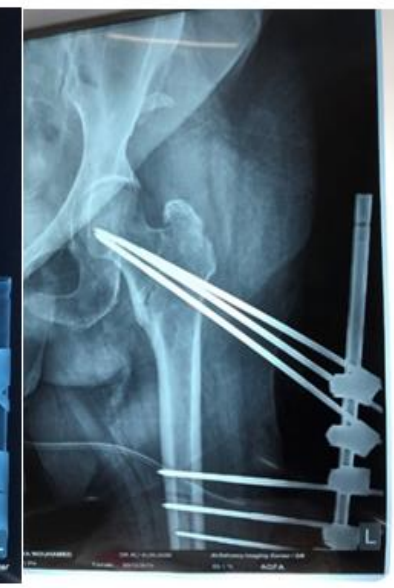

B
Figure 2: A- United grade I intertrochanteric fracture 4 months after surgery with two pins in neck of femur, B- United grade I intertrochanteric fracture 4 months after surgery with three pins in neck of femur.

The external fixation was removed under sedation and analgesia at the end of the $4^{\text {th }}$ postoperative month when the fracture united. The patients follow-up done every two months for a six months, looking for joints movements, union, deformity, shortening and evidence of infection.

The patients reported history of diabetes mellitus in 11 patients, hypertension in 9 patients, ischemic heart disease in 7 patients, 2 had cerebrovascular diseases, and 2 had chronic pulmonary diseases.

\section{RESULTS}

The mean of follow-up of patients were 11 months ranged from 6- 24 months. The operative time mean were 32 minutes ranged from 20- 55 minutes, there was minimal blood loss. Twenty two patients got bone union by the end of $4^{\text {th }}$ month, all external fixator devices removed by the end of fourth postoperative month (Figure $3 \mathrm{a}, \mathrm{b}$ ) , (Figure 4). Two patients died due to unrelated medical diseases (one patient died from acute renal failure and the other from ischemic heart disease). One diabetic patient developed pathological fracture in femoral shaft with infection in bone around pins which was treated conservatively by antibiotics and traction, one patient didn't tolerate the external fixation and the fixator removed in forth postoperative week and treated by skin traction. There was no pin breakage, loosening, or femoral head penetration. Eighteen patients developed pin tract infections. All pin tract infection was superficial and responded well to oral antibiotics and pin site care, and healed after removal of pins within two weeks, except in one diabetic patient who developed osteomyelitis of femoral shaft and pathological fracture. The external fixator was annoying to the patients but they could sit and lay down without difficulties. The patients discharged from hospital in first or second postoperative day.

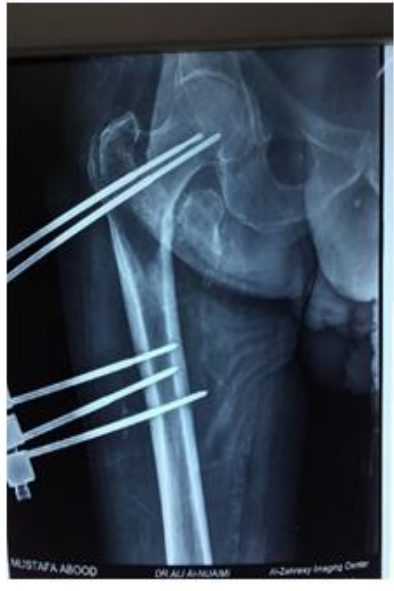

A

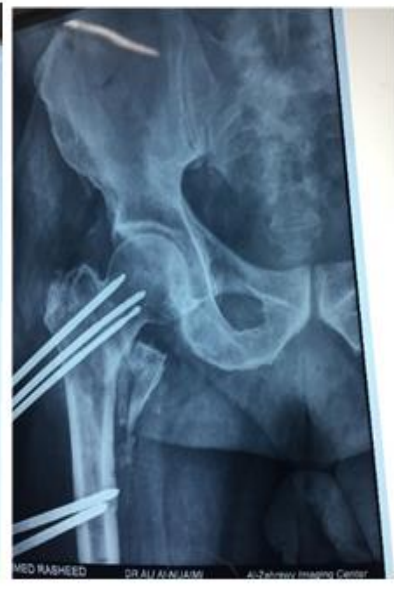

B
Figure 3: A, B- united intertrochanteric fractures 4 months after surgery.

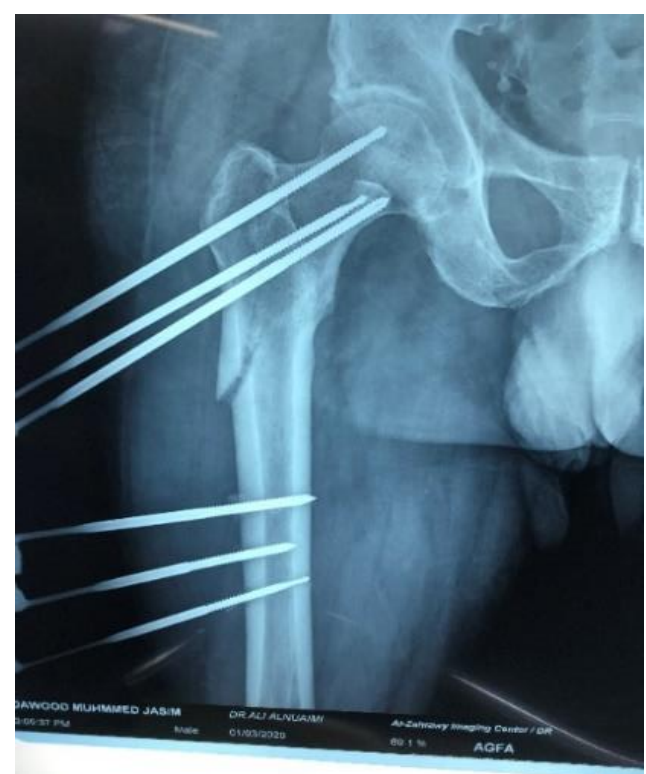

Figure 4: United unstable reverse grade IV intertrochanteric fractures 4 months after surgery. 
All patients had normal range of movement in hip and knee joints in last follow-up, all were able to walk independently without or with walking aids.

There was no detectable shortening of limb or varus deformity. Temporary stiffness in the ipsilateral knee was noticed in presence of external fixation and resolved spontaneously with mobilization after removal of the fixator. The pin site wound healed spontaneously within two weeks after removal of pin.

\section{DISCUSSION}

Our report is a case series on intertrochanteric fractures of femoral neck treated by $A O$ external fixation, the results in last follow-up is good and encouraging the use of this simple technique in treatment of this common fracture. During the time of this study, Mosul was just liberated from ISIS occupation, and faced massive destruction of all infrastructures in the city, including damage of all hospitals, with shortage in all economic, medical and surgical facilities. The only available surgical fixation for intertrochanteric fractures that could be used was the external fixator. The aim of treatment in intertrochanteric fractures is early mobilization and to restore patients preoperative status and to decrease patients mortality and morbidity ${ }^{2}$.

The external fixation used widely for high risk patients with intertrochanteric fractures to minimized the surgical trauma, to avoid the major surgery of internal fixation, and to avoid complications of conservative treatment to reduce the mortality and morbidity of this injury ${ }^{4-6,8}$. In developing countries, where there is shortage of surgical facilities and hospitals with patients in need for operative treatment, external fixation of intertrochanteric fractures is a good option 2, 7, 9 . The short time of surgery, minimal blood loss, short hospitalization, early mobilization, and acceptable tolerance by patients is confirmed by results of other similar studies ${ }^{2,5,6,8-12}$. By end of $4^{\text {th }}$ month all fractures in our patients were united, there was no delayed union. The number of our case series is small but the benefit of external fixation in intertrochanteric fractures shown by simple, miniinvasive, minimal blood loss, preservation of fracture hematoma, short time of surgery, less aggressive, cheap, short hospitalization, allow early mobilization, avoidance of large incision and avoid another surgical procedure ${ }^{5-14}$.

The external fixation is effective alternative method in the treatment of intertrochanteric fractures of femoral neck in developing countries with limited resources, especially at time of crises ${ }^{2}$, 7, 9, 14
The common complication noticed in this series was pin tract infections, which is expected as the diabetes mellites is the common comorbidity in our patients, all responded well to oral antibiotics and local care and healed in 10 days after removal of pin, except one patient who developed pathological fracture of femoral shaft. Our results are comparable with other reports ${ }^{2,5-7,9,12,14,15}$.

The delaying of weight bearing until bone start united, and using stable fixation decrease the varus deformation of the hip and shortening of fractured limb. This is similar to other reports $7,9,14$. The higher incidence of pin tract infection in our patients can be explained by high incidence of diabetes mellitus as comorbidity, all diabetic patients developed pin tract infection. When external fixation is used for intertrochanteric fractures, prolonged recumbency in bed complications and complications of open reduction and internal fixation can be avoided ${ }^{2}$. The drawback is the inconvenience to the patient with using external fixator and the high rate of pin site-related infection ${ }^{2}$.

In conclusion, intertrochanteric fracture of femoral neck can be treated by external fixation as it is minimally invasive, safe, cheap, simple, with less blood loss, shorter operative time, shorter hospitalization, and avoid complications associated with long bed ridden and internal fixation. External fixation in intertrochanteric fractures had good results and can be used in adverse state when there is shortage of implant and surgical facilities.

\section{REFERENCES}

1.Baker R, Whitehouse M. Injuries of the hip and femur. In: Blom A, Warwick D, Whitehouse MR. APLEY\& SOLOMON'S System of Orthopaedics and Trauma. $10^{\text {th }}$ ed. 20018 . CRC press. New York. : 886-897.

2. Gani N, Kangoo KA, Bashir A, Muzaffer R, Bhat M F, Faroog $M$ et al. External fixation of "intertrochanteric" fractures. Orthop Rev (Pavia). 2009 ; 10; 1(2): e18. Published online 2009 Oct 10. doi: [10.4081/or.2009.e18].

3.Scott H. I. Treatment of intertrochanteric fractures by skeletal pinning and external fixation. Clin. Orthop., 1957,10, 326-334.

4.Arslan A, Utkan A, Koca $T T$. Results of a compression pin along with trochanteric external fixation in management of high risk elderly intertrochanteric fractures. Indian J Orthop. 2016;50(6):636-640.

5.Kazakos K, Lyras DN, Verettas D, Galanis V, Psillakis I, Xarchas K. External fixation of 
intertrochanteric fractures in elderly high-risk patients. Acta Orthop Belg. 2007;731):44-8.

6. Wang ZP, Liu L, Xue W, Zhou HR, Song YX, Cai $L Y$, Cheng XT, Qian YW. Curative effect analysis on closed reduction and external fixator under local anesthesia for the treatment of intertrochanteric fracture in elderly patients with high-risk . Zhongguo Gu Shang. 2016;29(6):5024.

7. Elmowafy $\mathrm{H}$, Abd Elsattar $\mathrm{T}$, Darwish $\mathrm{A}$, Elreweny M . Management of intertrochanteric fracture in elderly high-risk patients using simple external fixation. Menoufia Med J, 2014; 27: 249254.

8. Guo L, Fan SW. Minimal invasion and closed reduction with external fixation for elderly femoral intertrochanteric fracture. Zhongguo Gu Shang. 2015; 28 (11):1048-52.

9. Yousry $A H$, Chotai $P N$, El Ghazaly $S A$, Fayyad T A, Abdelgawad A A. Outcomes of trochanteric external fixation for geriatric intertrochanteric hip fractures. J Orthop. 2015; 12(4): 174-178.

10. Polat M, Arslan A, Utkan A. External Fixation Versus Hemiartroplasty In Unstable Intertrochanteric Hip Fractures Of The Elderly. Acta Orthop Belg. 2017 ;83(3):351-359.

11. Zhang $Y$, Dong $Q$, Sun $X$, Hu F. External fixation versus dynamic hip screw in treatment of elderly intertrochanteric hip fractures: A systematic review and meta-analysis. J Orthop Sci. 2016;21(6):841-846.

12. Kazemian GH, Manafi AR, Najafi F, Najafi MA. Treatment of intertrochanteric fractures in elderly highrisk patients: dynamic hip screw vs. external fixation. Injury. 2014;45(3):568-72.

13. Inal S, Taspinar F, Gulbandilar E, Gok K. Comparison of the biomechanical effects of pertrochanteric fixator and dynamic hip screw on an intertr:chanteric femoral fracture using the finite element method. Int $\mathrm{J}$ Med Robot. 2015;11(1):95-103.

14. Pathania V $\mathrm{P}$, , Balakrishnan $M$, Khare $R$,External fixation of intertrochanteric fractures of femur in elderly. Med J Armed Forces India. 1999; 55(4): 325-327.

15. Subasi M, Kesemenli, Kapukaya A, Necmiogku S. Treatment of intertrochanteric fractures by external fixation. Acta Orthopædica Belgica 2001; $67: 470-476$. 